\title{
DISTRIBUTION OF CUTANEOUS LEISHMANIASIS BY SEX, AGE GROUPS AND RESIDENCE IN YEAR 2020 IN CUTANEOUS LEISHMANIASIS POPULATION OF DISTRICT D.I.KHAN, PAKISTAN
}

\author{
Muhammad Rashid', Younas Rehman', Muhammad Usman', Muhammad Younas', Muhammad Bilal', \\ Muhammad Jamil', Amanullah Khan², Zeeshan Khan'1, Abdul Wahid', Najeeb Ullah', Hayat Ullah', Zohaib \\ Khan Afridi', Asghar Khan', Asad Ullah'1 \\ ${ }^{1}$ Students, ${ }^{2}$ Department of Community Medicine, Gomal Medical College, D.I.Khan, Pakistan
}

\begin{abstract}
Background: Leishmaniasis is not an uncommon tropical disease. Cutaneous leishmaniasis is its most common form. The objectives of our study were to determine the distribution of cutaneous leishmaniasis by sex, age groups and residence in year 2020 in cutaneous leishmaniasis population of District D.I.Khan, Pakistan.

Materials \& Methods: This cross-sectional study was conducted in Department of Community Medicine, Gomal Medical College, D.I.Khan, Pakistan from January 1, 2021 to January 23, 2021. The data for cutaneous leishmaniasis was retrieved from District Health Office, D.I.Khan for year 2020. A sample size of 419 was calculated from population at risk of $1,750,000$ with $0.1034 \%$ margin of error, $95 \%$ confidence level and $0.01164 \%$ assumed prevalence of cutaneous leishmaniasis. Sex, age groups and residence were our three nominal variables. Distribution was analyzed by count and percentage with $95 \%$ confidence intervals. Three hypotheses for distribution were testified by chi-square goodness of Fit test.

Results: Out of 419 positive cases of cutaneous leishmaniasis, 269 (64.20\%) were men and $150(35.80 \%)$ women, $254(60.62 \%)$ were in age group up to 19 years, $101(24.11 \%)$ in age group 20-39 years and $64(15.27 \%)$ in age group $\geq 40$ years, and $113(26.97 \%)$ were urban and $306(73.03 \%)$ rural. Our distribution by sex $(p=0.01327)$, age groups $(p=<0.0001)$ and residence $(p=<0.0001)$ were not similar to expected.

Conclusions: The prevalence of cutaneous leishmaniasis in year 2020 in cutaneous leishmaniasis population of District D.I.Khan, Pakistan was higher in men than women, highest in age group up to 19 years than age groups 20-39 and $\geq 40$ years, and higher in rural than urban. The prevalence for men was higher than expected for men and prevalence for women was lower than expected for women. The prevalence for age group up to 19 years was highest than expected for this age group than age groups 20-39 and $\geq 40$ years. The prevalence for rural was higher than expected for rural and the prevalence for urban was lower than expected for urban.
\end{abstract}

KEY WORDS: Cutaneous Leishmaniasis; Leishmania Donovani; Distribution; Sex; Age Groups; Residence; Pakistan; Urban; Rural; Skin.

Cite as: Rashid M, Rehman Y, Usman M, Younas M, Bilal M, Jamil M, et al. Distribution of cutaneous leishmaniasis by sex, age groups and residence in year 2020 in cutaneous leishmaniasis population of District D.I.Khan, Pakistan. Gomal J Med Sci 2021 Jan-Mar; 19(1):28-34. https://doi.org/10.46903/gjms/19.01.964

\section{INTRODUCTION}

\subsection{Background}

We have placed the burden of cutaneous leishmaniasis (CL) as distributed by sex, age groups and

\section{Corresponding Author:}

Muhammad Rashid

Student, Gomal Medical College

D.I.Khan, Pakistan

E-mail: m.rashid4753@gmail.com

Date Submitted: 25-01-2021

Date Revised: $\quad 15-02-2021$

Date Accepted: $\quad 20-02-2021$ residence from global and regional studies and then from national and local studies.

Armijos, et al. ${ }^{1}$ from area of subtropical rainforest in North-West Ecuador showed the prevalence of confirmed cases of CL as $13.95 \%$ (65/466).

Omari, et al. ${ }^{2}$ from Fez-Meknes region, Central Morocco for the period from 2009-2015 reported 70 confirmed cases of CL, including 38 (54.29\%) urban and $32(45.71 \%)$ rural.

Aksoy, et al. ${ }^{3}$ from Sanliurfa, Turkey for the period from 1998-2014 reported 8,786 confirmed cases of $\mathrm{CL}$, including $4,050(46.10 \%)$ men and 4,736 $(53.90 \%)$ woman, and 3,098 (35.26\%) cases in age 
group up to 5 years, $3,464(39.43 \%)$ in age group $6-10$ years and $2,224(2224 * 100 / 8786=25.31 \%)$ in age group 11-15 years.

Rajapaksa, et al. ${ }^{4}$ from Matara and Hambanthota districts of Southern Province of Sri Lanka reported in 2006 a sample of 113 confirmed cases of $\mathrm{CL}$, including $57(50.44 \%)$ men $(57 * 100 / 113=50.44)$ and $56(49.56 \%)$ women $(56 * 100 / 113=49.56)$, and 42 $(37.17 \%)$ in age group up to 19 years, $26(23.01 \%)$ in age group 20-39 years and 45 (39.82\%) in age group $\geq 40$ years.

Ayaz, et al. ${ }^{5}$ published a report from Metropolitan City of Multan, Pakistan in 2018 and showed 198 positive cases of CL including 101 (51.01\%) men and 97 (48.99\%) women.

Hayat, et al. ${ }^{6}$ from District Dir, Khyber Pakhtunkhwa, Pakistan reported 300 confirm cases of CL in July-August 2013, including 171 (57\%) men and 129 (43\%) women, and 142 (47\%) in age group up to 15 years, $84(28 \%)$ in age group 16-30 years and $75(25 \%)$ in age group $\geq 31$ years.

Rahim, et al. ${ }^{7}$ from village Wantangi, District Dir, Pakistan reported 37 positive cases of $\mathrm{CL}$ in August 2001 , including $34(85 \%)$ cases in age group up to 20 years, $5(12.5 \%)$ in age group 21-40 years and 1 $(2.5 \%)$ in age group $40-60$ years.

Jamal, et al. ${ }^{8}$ from Dargai Tehsil of Malakand, Khyber Pakhtunkhwa, Pakistan reported 102 confirm cases of $\mathrm{CL}$ reported in 2013, including $72(70.59 \%)$ men and $30(29.41 \%)$ women, and $48(47.06 \%)$ in age group up to 20 years, $33(32.35 \%)$ in age group 21 40 years and 21 (20.59\%) in age group $\geq 40$ years.

Ullah, et al. ${ }^{9}$ from Peshawer Pakistan reported 9,631 CL patients spanning from April 2011-Octbar 2014, including 5,605 (58.20\%) men and 4,026 (41.80\%) women.

Hussain, et al..$^{10}$ from-war affected Wazirastan areas of Pakistan surveyed a sample of 7,548 persons during 2013-2015 from different endemic areas of North Waziristan and South Waziristan agencies and reported $273(3.61 \%)$ positive cases of CL.

\subsection{Research Problems (RPs)}

We do not know the distribution of cutaneous leishmaniasis by sex, age groups and residence in year 2020 in cutaneous leishmaniasis population of District D.I.Khan. This unawareness of three pieces of information were our three RPs.

\subsection{Knowledge Gaps, Rationale \& Research Questions (RQs)}

Relevant research documents regarding our RPs could not be found by online search through various search engines and data bases. These were our three KGs and rationale of the study.

What would be the distribution of CL by sex, age groups and residence in year 2020 in CL population of District D.I.Khan would be our three RQs.

\subsection{Research Objectives (ROs)}

The objectives of our study were to determine the:

RO 1: distribution of cutaneous leishmaniasis (CL) by sex in year 2020 in cutaneous leishmaniasis population of District D.I.Khan Pakistan.

RO 2: distribution of CL by age groups in year 2020 in cutaneous leishmaniasis population of District D.I.Khan Pakistan.

RO 3: distribution of CL by residence in year 2020 in cutaneous leishmaniasis population of District D.I.Khan Pakistan.

\subsection{Null Hypotheses}

Following three null hypotheses were formulated from literature. These were tentative answers to our three RQs. Accordingly, we collected data for relevant variables, analyzed and interpret these to get observed answers for our research questions, which filled our three knowledge gaps and solved our three research problems.

$\mathbf{H}_{\mathrm{O} 1}$ : The observed distribution of cutaneous leishmaniasis (CL) by sex in year 2020 in cutaneous leishmaniasis population of District D.I.Khan Pakistan is similar as expected.

$\mathrm{H}_{\mathrm{O} 2}$ : The observed distribution of $\mathrm{CL}$ by age groups in year 2020 in cutaneous leishmaniasis population of District D.I.Khan Pakistan is similar as expected.

$\mathbf{H}_{\mathrm{O}_{3}}$ : The observed distribution of $\mathrm{CL}$ by residence in year 2020 in cutaneous leishmaniasis population of District D.I.Khan Pakistan is similar as expected.

\subsection{Significance}

Until we know the overall and group wise burden of a disease, we cannot optimally allocate the required and available resources. Through this cross-sectional inquiry, we can determine the distribution of CL by sex, age groups and residence and then recommend to the service providers (government and NGOs) to allocate their resources optimally to combat cutaneous leishmaniasis. Further, this investigation will help in further research by providing baseline data.

\section{MATERIALS AND METHODS}

\subsection{Design, Setting \& Duration}

This descriptive study was conducted in the Department of Community Medicine, Gomal Medical College, D.I.Khan, Pakistan from January 1, 2021 to January 23,2021 . This research project was approved by the "Research Evaluation and Ethics Committee of this Institute". Ethical approval was not required as it was record-based study. This project was supervised by Dr. Muhammad Marwat of this institute.

\subsection{Population, Sample Size \& Technique and Sample Selection}

The population of District D.I Khan, Pakistan was $1,627,132$ as per census 2017. For the year 2020, 
it is estimated to be around 1.75 million. District Health Office, D.I.Khan and three Tehsil HQ Hospitals; Kulachi, Paroa and Paharpur are providing curative facilities for $\mathrm{CL}$ in District D.I.Khan. Out of 1.75 million population, a sample size of 419 was calculated, with $0.1034 \%$ margin of error, $95 \%$ confidence level, assumed prevalence of CL $0.01164 \%,{ }^{4}$ using an online calculator Raosoft ${ }_{\circledast}^{11}$ through consecutive sampling technique.

\section{Inclusion Criteria}

All diagnosed patients of cutaneous leishmaniasis of district D.I. Khan were eligible for inclusion in this study. The diagnosis was confirmed by isolation of LD bodies from skin lesions.

\section{Exclusion Criteria}

No subject was excluded.

2.3 Conduct of Procedure: DHO office, D.I.Khan maintains the record of cutaneous leishmaniasis. The data for cutaneous leishmaniasis was retrieved from this office in Excel spreadsheet for the duration of 1-1-2020 to 31-12-2020.

\subsection{Data Collection Plan}

Sex (men and women), age groups (up to 19 years, 20-39 years $\& \geq 40$ years) and residence (urban and rural) were our three nominal variables.

\subsection{Data Analysis Plan}

\subsubsection{Descriptive Statistics and Estimation of} Parameters: Sample's distribution was described by count and percentage. Population distribution was described by $95 \% \mathrm{Cl}$ using normal approximation method through an online statistical calculator "Statistics Kingdom". ${ }^{12}$ The comparison between the attributes/groups/ categories was based on overlapping of confidence intervals in results and also in discussion.

2.5.2 Hypotheses Testing: Adjusted expected counts and percentages for distribution by sex, age groups and residence were calculated. Three hypotheses $\left(\mathrm{H}_{01}\right.$ to $\left.\mathrm{H}_{03}\right)$ for distribution of $\mathrm{CL}$ by sex, age groups and residence were verified each by chisquare goodness-of-fit test. Observed \& expected counts and their difference, with chi-square value, degree of freedom and $p$-value were shown at alpha .05 by an online statistical calculator. ${ }^{13}$

\section{RESULTS}

\subsection{Descriptive Analysis \& Estimation of Param- eters}

3.1.1 Distribution of positive cases of cutaneous leishmaniasis by sex, age groups and residence

The distribution of positive cases of CL by sex, age groups and residence in cutaneous leishmaniasis population of District D.I.Khan is shown in Table 3.1.1. Out of 419 positive CL cases, 269 (64.20\%) were men and 150 (35.80\%) women, and 254 (60.62\%) were in age group up to 19 years, $101(24.11 \%)$ in age group 20-39 years and $64(15.27 \%)$ in age group $\geq 40$ years, and $133(26.97 \%)$ were urban and 306 (73.03\%) were rural. Here the prevalence of cutaneous leishmaniasis in sample was higher in men (64.20\%, 95\% Cl 59.61-68.79) than women (35.80\%, $95 \% \mathrm{Cl} 31.21-40.39)$, and higher in age group up to 19 years $(60.62 \%, 95 \% \mathrm{Cl} 55.94-65.30)$ than age group $20-39$ years $(24.11 \%, 95 \% \mathrm{Cl} 20.01-28.20)$ and age group $\geq 40$ years $(15.27 \%, 95 \% \mathrm{Cl} 11.83-18.72)$, and higher in rural $(73.03 \%, 95 \% \mathrm{Cl} 68.78-77.28)$ than urban (26.97\%, 95\% Cl 22.72-31.22).

\subsection{Hypotheses Testing}

3.2.1 Observed vs. expected distribution of positive cases of cutaneous leishmaniasis by $\operatorname{sex}\left(\mathrm{H}_{01}\right)$ Our observed distribution for men versus women was 269:150 out of 419 positive cases of CL against expected distribution of $5,605: 4,026$ out of 9,631 positive cases of CL from study by Ullah, et al. ${ }^{8}$ Having different sample sizes/ denominators, comparison was not justified. Then we adjusted the expected counts \& percentages for a sample of 419 . The expected counts of 5,605:4,026 were replaced by

Table 3.1.1 Distribution of positive cases of cutaneous leishmaniasis by sex, age groups and residence in cutaneous leishmaniasis population of District D.I.Khan, Pakistan $(n=419)$

\begin{tabular}{|l|l|c|c|c|c|}
\hline \multirow{2}{*}{ Variables } & \multirow{2}{*}{ Attributes } & \multicolumn{2}{|c|}{ Sample statistics } & \multicolumn{2}{c|}{ 95\% Cl for proportion } \\
\cline { 3 - 6 } & & Count & Percentage & Lower & Upper \\
\hline \multirow{2}{*}{ Sex } & Men & 269 & $64.20 \%(269 * 100 / 419=64.20)$ & 59.61 & 68.79 \\
\cline { 2 - 6 } & Women & 150 & $35.80 \%(150 * 100 / 419=35.80)$ & 31.21 & 40.39 \\
\hline \multirow{3}{*}{ Age groups } & Up to 19 years & 254 & $60.62 \%\left(254^{*} 100 / 419=60.62\right)$ & 55.94 & 65.30 \\
\cline { 2 - 6 } & $20-39$ years & 101 & $24.11 \%(101 * 100 / 419=24.11)$ & 20.01 & 28.20 \\
\cline { 2 - 6 } & $\geq 40$ years & 64 & $15.27 \%(64 * 100 / 419=15.27)$ & 11.83 & 18.72 \\
\hline \multirow{2}{*}{ Residence } & Urban & 113 & $26.97 \%\left(113^{*} 100 / 419=26.97\right)$ & 22.72 & 31.22 \\
\hline \multirow{2}{*}{ Total } & Rural & 306 & $73.03 \%(306 * 100 / 419=73.03)$ & 68.78 & 77.28 \\
\hline
\end{tabular}


adjusted expected counts of 244:175 and adjusted percentages were similar as the expected percentages. (Table 3.2.1.1)

Chi-square goodness-of-fit test gave p-value less than .05. Hence $\mathrm{H}_{01}$ was rejected, showing that the observed distribution did not match the expected distribution. Simply, our observed distribution of $\mathrm{CL}$ in men $64.20 \%$ was statistically higher than what we expected (adjusted expected) for men 58.20\% \& our observed distribution in women $35.80 \%$ was less than what we expected (adjusted expected) for women $41.80 \%$ from Ullah, et al. ${ }^{15}$ (Table 3.2.1.2)

3.2.2 Observed vs. expected distribution of positive cases of cutaneous leishmaniasis by age groups $\left(\mathbf{H}_{02}\right)$

Our observed distribution for age group up to 19 years versus $20-39$ years and $\geq 40$ years was 254 : 101:64 out of 419 positive cases against expected distribution of 48:33:21 in age group of up to 19 years versus $20-39$ years and $\geq 40$ years out of 102 positive cases of CL as showed by Jamal, et al. ${ }^{7}$ Having different sample sizes/ denominators, comparison was not justified. Then we adjusted the expected counts \& percentages for a sample of 419. The expected counts of 48:33:21 were replaced by adjusted expected counts of 197:136:86 and expected percentages $47.05 \%: 32.36 \%: 20.59 \%$ were replaced by adjusted expected percentages 47.01\%:32.46\%:20.53\% respectively. (Table 3.2.2.1)

Chi-square goodness of Fit test gave p-value less than $.05 . \mathrm{H}_{02}$ was rejected, showing that the observed distribution did not match the expected distribution. It simply means that our observed distribution of CL in age group of up to 19 years $60.62 \%$ was statistically higher than what we expected for age group of up to 19 years $47.01 \%$ (adjusted expected) and our observed distribution in age group 20-39 years

Table 3.2.1.1 Observed, expected and adjusted expected counts and percentages for distribution of positive cases of cutaneous leishmaniasis by sex in 2020 in cutaneous leishmaniasis population of District D.I.Khan, Pakistan $(n=419)$

\begin{tabular}{|l|l|c|c|c|c|c|}
\hline Presence of $\mathrm{CL}$ & $\begin{array}{l}\text { Observed } \\
\text { counts (O) }\end{array}$ & $\begin{array}{c}\text { Observed } \\
\text { \%ages }\end{array}$ & $\begin{array}{c}\text { Expected } \\
\text { counts }\end{array}$ & Expected \%ages & $\begin{array}{c}\text { Adjusted expect- } \\
\text { ed counts (E) }\end{array}$ & $\begin{array}{c}\text { Adjusted } \\
\text { expected \% }\end{array}$ \\
\hline $\begin{array}{l}\text { Positive cases in } \\
\text { Men }\end{array}$ & 269 & $\begin{array}{c}269 * 100 / 419 \\
=64.20 \%\end{array}$ & 5,605 & $\begin{array}{c}5,605^{*} 100 / 9,631 \\
=58.20 \%\end{array}$ & $\begin{array}{c}5,605 * 419 / 9,631 \\
=244\end{array}$ & $\begin{array}{c}244^{*} 100 / 419 \\
=58.20 \%\end{array}$ \\
\hline $\begin{array}{l}\text { Positive cases in } \\
\text { Women }\end{array}$ & 150 & $\begin{array}{c}150 * 100 / 419 \\
=35.80 \%\end{array}$ & 4,026 & $\begin{array}{c}4,026 * 100 / 9,631 \\
=41.80 \%\end{array}$ & $\begin{array}{c}4,026 * 419 / 9,631 \\
=175\end{array}$ & $\begin{array}{c}175 * 100 / 419 \\
=41.80 \%\end{array}$ \\
\hline Total positive & 419 & $100 \%$ & 9,631 & $100 \%$ & 419 & $100 \%$ \\
\hline
\end{tabular}

Table 3.2.1.2 Observed vs. expected distribution of positive cases of cutaneous leishmaniasis by sex in 2020 in cutaneous leishmaniasis population of District D.I.Khan, Pakistan $\left(H_{01}\right)(n=419)$

\begin{tabular}{|l|l|c|c|c|c|c|c|c|c|}
\hline Variable & Attributes & $\mathrm{O}$ & $\mathrm{E}$ & $\mathrm{O}-\mathrm{E}$ & $(\mathrm{O}-\mathrm{E})^{2}$ & $(\mathrm{O}-\mathrm{E})^{2} / \mathrm{E}$ & $\mathrm{X}^{2}$ & d.f. & $\mathrm{p}$-value \\
\hline \multirow{2}{*}{ Sex } & Men & 269 & 244 & 25 & 625 & 2.56 & 6.133 & 1 & 0.01327 \\
\cline { 2 - 9 } & Women & 150 & 175 & -25 & 625 & 3.57 & \multicolumn{2}{|c|}{$\mathrm{H}_{01}$ rejected at alpha .05} \\
\hline \multirow{2}{*}{ Total } & 419 & 419 & \multicolumn{5}{c|}{ Chi-square-goodness-of-fit test with Yates correction } \\
\hline
\end{tabular}

$\mathrm{O}=$ Observed count, $\mathrm{E}=$ Expected count, $\mathrm{X}^{2}=$ chi-square statistic, $\mathrm{d} . \mathrm{f}=$ degree of freedom

Table 3.2.2.1: Observed, expected and adjusted expected counts and percentages for distribution of positive cases of cutaneous leishmaniasis by age groups in 2020 in cutaneous leishmaniasis population of District D.I.Khan, Pakistan $(n=419)$

\begin{tabular}{|c|c|c|c|c|c|c|}
\hline Presence of $\mathrm{CL}$ & $\begin{array}{l}\text { Observed } \\
\text { counts (O) }\end{array}$ & $\begin{array}{l}\text { Observed } \\
\text { \%ages }\end{array}$ & $\begin{array}{l}\text { Expected } \\
\text { counts }\end{array}$ & $\begin{array}{l}\text { Expected } \\
\text { \%ages }\end{array}$ & $\begin{array}{l}\text { Adjusted expect- } \\
\text { ed counts (E) }\end{array}$ & $\begin{array}{l}\text { Adjusted } \\
\text { expected \% }\end{array}$ \\
\hline $\begin{array}{l}\text { Positive cases in age } \\
\text { group up to } 19 \text { years }\end{array}$ & 254 & $\begin{array}{c}254 * 100 / 419 \\
=60.62 \%\end{array}$ & 48 & $\begin{array}{l}48 * 100 / 102 \\
=47.05 \%\end{array}$ & $\begin{array}{l}48^{*} 419 / 102 \\
\quad=197\end{array}$ & $\begin{array}{l}197 * 100 / 419 \\
\quad=47.01\end{array}$ \\
\hline $\begin{array}{l}\text { Positive cases in age } \\
\text { group 20-39 }\end{array}$ & 101 & $\begin{array}{c}101 * 100 / 419 \\
=24.11 \%\end{array}$ & 33 & $\begin{array}{c}33^{*} 100 / 102 \\
=32.36 \%\end{array}$ & $\begin{array}{l}33 * 419 / 102 \\
=136\end{array}$ & $\begin{array}{l}136 * 100 / 419 \\
=32.46\end{array}$ \\
\hline $\begin{array}{l}\text { Positive cases in age } \\
\text { group } \geq 40 \text { years }\end{array}$ & 64 & $\begin{array}{l}64 * 100 / 419 \\
=15.27 \%\end{array}$ & 21 & $\begin{array}{l}21 * 100 / 102 \\
=20.59 \%\end{array}$ & $21 * 419 / 102=86$ & $\begin{array}{l}86 * 100 / 419 \\
=20.53\end{array}$ \\
\hline Total positive & 419 & $100 \%$ & 102 & $100 \%$ & 419 & $100 \%$ \\
\hline
\end{tabular}


Muhammad Rashid, et al.

Table 3.2.2.2: Observed vs. expected distribution of positive cases of cutaneous leishmaniasis by age groups in 2020 in cutaneous leishmaniasis population of District D.I.Khan, Pakistan $(n=419)$

\begin{tabular}{|c|c|c|c|c|c|c|c|c|c|}
\hline Variable & Attributes & $\mathrm{O}$ & $E$ & O-E & $(O-E)^{2}$ & $(\mathrm{O}-\mathrm{E})^{2} / \mathrm{E}$ & $x^{2}$ & d.f. & $\mathrm{p}$-value \\
\hline \multirow{3}{*}{ Age groups } & Up to 19 years & 254 & 197 & 57.00 & 3249.00 & 16.49 & 31.128 & 2 & $<0.0001$ \\
\hline & 20-39 years & 101 & 136 & -35.00 & 1225.00 & 9.01 & \multirow{2}{*}{\multicolumn{3}{|c|}{$\mathrm{H}_{02}$ rejected at alpha .05}} \\
\hline & $\geq 40$ years & 64 & 86 & -22.00 & 484.00 & 5.63 & & & \\
\hline \multicolumn{2}{|l|}{ Total } & 419 & 419 & \multicolumn{6}{|c|}{ Chi-square goodness of fit test with Yates correction } \\
\hline
\end{tabular}

$\mathrm{O}=$ Observed count, $\mathrm{E}=$ Expected count, $\mathrm{X}^{2}=$ chi-square statistic, $\mathrm{d} . \mathrm{f}=$ degree of freedom

Table 3.2.3.1: Observed, expected and adjusted expected counts and percentages for distribution of positive cases of cutaneous leishmaniasis by residence in 2020 in cutaneous leishmaniasis population of District D.I.Khan, Pakistan $(n=419)$

\begin{tabular}{|l|l|l|c|c|c|c|}
\hline $\begin{array}{l}\text { Presence } \\
\text { of CL }\end{array}$ & $\begin{array}{l}\text { Observed } \\
\text { counts (O) }\end{array}$ & $\begin{array}{l}\text { Observed } \\
\% \text { ages }\end{array}$ & $\begin{array}{c}\text { Expected } \\
\text { counts }\end{array}$ & Expected \%ages & $\begin{array}{l}\text { Adjusted expect- } \\
\text { ed counts (E) }\end{array}$ & Adjusted expected \% \\
\hline Urban & 113 & $\begin{array}{l}113^{\star} 100 / 419 \\
=26.97 \%\end{array}$ & 38 & $38 * 100 / 70=54.29 \%$ & $38 * 419 / 70=227$ & $227 * 100 / 419=54.18$ \\
\hline Rural & 306 & $\begin{array}{l}306 * 100 / 419 \\
=73.03 \%\end{array}$ & 32 & $32 * 100 / 70=45.71 \%$ & $32 * 419 / 70=192$ & $192 * 100 / 419=45.82$ \\
\hline Total & 419 & $100 \%$ & 70 & $100 \%$ & 419 & $100 \%$ \\
\hline
\end{tabular}

Table 3.2.3.2: Observed vs. expected distribution of positive cases of cutaneous leishmaniasis by residence in 2020 in cutaneous leishmaniasis population of District D.I.Khan, Pakistan $(n=419)$

\begin{tabular}{|l|l|c|c|c|c|c|c|c|c|}
\hline Variable & Attributes & $\mathrm{O}$ & $\mathrm{E}$ & $\mathrm{O}-\mathrm{E}$ & $(\mathrm{O}-\mathrm{E})^{2}$ & $(\mathrm{O}-\mathrm{E})^{2} / \mathrm{E}$ & $\mathrm{X}^{2}$ & d.f. & $\mathrm{p}$-value \\
\hline \multirow{2}{*}{ Residence } & Urban & 113 & 227 & -114.00 & 12996.00 & 57.25 & 124.939 & 1 & $<0.0001$ \\
\cline { 2 - 9 } & Rural & 306 & 192 & 114.00 & 12996.00 & 67.69 & $\mathrm{H}_{03}$ rejected at alpha .05 \\
\hline
\end{tabular}

$\mathrm{O}=$ Observed count, $\mathrm{E}=$ Expected count, $\chi^{2}=$ chi-square statistic, d.f. $=$ degree of freedom

$24.11 \%$ was lower than what we expected for age group 20-39 years $32.46 \%$ (adjusted expected) and our observed distribution in age group $\geq 40$ years $15.27 \%$ was lower than what we expected for age group $\geq 40$ years $20.53 \%$ (adjusted expected). (Table 3.2.2.2)

3.2.3 Observed vs. expected distribution of positive cases of cutaneous leishmaniasis by residence $\left(\mathrm{H}_{03}\right)$

Our observed distribution for urban versus rural was 113:306 out of 419 positive cases against expected distribution of $38: 32$ in urban versus rural out of 70 positive cases of CL as reported by Omari, et al. ${ }^{2} \mathrm{Hav}$ ing different sample sizes/ denominators, comparison was not justified. Then we adjusted the expected counts \& percentages for a sample of 419 . The expected counts of $38: 32$ were replaced by $227: 192$ and expected percentages of $54.29 \%: 45.71 \%$ were replaced by adjusted expected percentages of $54.18 \%: 45.82 \%$ respectively. (Table 3.2.3.1)

Chi-square goodness of Fit test gave p-value less than $.05 . \mathrm{H}_{03}$ was rejected, showing that the observed distribution did not match the expected distribution. It simply means that our observed distribution of $\mathrm{CL}$ in urban $26.97 \%$ was statistically lower than what we expected for urban $54.18 \%$ (adjusted expected) \& our observed distribution in rural $73.03 \%$ was higher than what we expected for rural $45.82 \%$ (adjusted expected) (Table 3.2.3.2)

\section{DISCUSSION}

4.1 Distribution of positive cases of cutaneous leishmaniasis by sex $\left(\mathrm{H}_{01}\right)$

The prevalence of $\mathrm{CL}$ in our study was more in men $269(64.20 \%, 95 \% \mathrm{Cl} 59.61 \%-68.79 \%)$ than women $150(35.80 \%, 95 \% \mathrm{Cl} 31.21 \%-40.39 \%)$ as per our confidence intervals.

Similar to our study with higher prevalence in men than women was reported by Jamal, et al. ${ }^{8}$ from Dargai Tehsil of Malakand, Khyber Pakhtunkhwa, Pakistan reported 102 confirm cases of cutaneous leishmaniasis reported in 2013, including 72 (70.59\%, $95 \% \mathrm{Cl} 60.75-79.20)$ men and $30(29.41 \%, 95 \%$ $\mathrm{Cl}$ 20.80-39.25) women and by Ullah, et al. ${ }^{9}$ from Peshawar, Pakistan reported 9,631 CL patients spanning from April 2011-October 2014 including $5605(58.20 \%, 95 \% \mathrm{Cl} 57.20-59.19)$ men and 4026 (41.80\%, 95\%Cl 40.81-42.80) women.

Unlike our study, there was similar prevalence of $\mathrm{CL}$ in men and women as reported by Ayaz, et al. ${ }^{5}$ from Meteropolitan city of Multan, Pakistan in 2018, showing 198 positive cases of CL including 101 (51.01\%, 
95\% Cl 44.05-57.97) men and 97 (48.99\%, 95\% Cl 42.03-55.95) women and Hayat, et al. ${ }^{6}$ from District Dir, Khyber Pakhtunkhwa, Pakistan reporting 300 confirmed cases of CL in July-August 2013, including $171(57 \%, 95 \% \mathrm{Cl} 42.03-55.95)$ men and 129 (43\%, $95 \% \mathrm{Cl} 37.32-48.81$ ) women.

No study with higher prevalence of $C L$ in women could be found.

Our observed distribution of $\mathrm{CL}$ in men was statistically higher than what we expected for men (adjusted expected) and our observed distribution of $C L$ in women was statistically lower than what we expected for women (adjusted expected). No studies with hypothesis testing were found on literature search.

\subsection{Distribution of positive cases of cutaneous leishmaniasis by age groups $\left(\mathrm{H}_{02}\right)$}

The prevalence of CL by age groups in our study was higher in age group up to 19 years 254 (60.62\%, 95\% Cl 55.94-65.30) than age group 20-39 years 101 (24.11\%, 95\% Cl 20.01-28.20) and age group $\geq 40$ years $64(15.27 \%, 95 \% \mathrm{Cl} 11.83-18.72)$ as per our confidence intervals.

Similar to our study with highest prevalence in age group up to 19 years than age group 20-39 years and age group $\geq 40$ years was reported by Rahim, et al. ${ }^{7}$ from village Wantangi, District Dir, Pakistan reporting 37 positive cases of CL in August 2001, including 34 (85\%, 95\% $\mathrm{Cl} 78.09-98.30)$ cases in age group up to 20 years, $5(12.5 \%, 95 \% \mathrm{Cl} 45.37-28.77)$ cases in age group $21-40$ years and 1 (2.5\%, 95\% $\mathrm{Cl} 25.22-79.28)$ case in age group above 40 years. Also similar report was by Jamal, et al. ${ }^{8}$ from Dargai Tehsil of Malakand, Khyber Pakhtunkhwa, Pakistan, with 102 cases of CL in 2013 , showing $48(47.06 \%, 95 \% \mathrm{Cl} 37.10-57.20)$ in age group up to 20 years, $33(32.35 \%, 95 \% \mathrm{Cl} 23.42$ $42.34)$ in age group $21-40$ years and 21 (20.59\%, 95\% $\mathrm{Cl} 13.22-29.73$ ) in age group $\geq 40$ years.

Contrary to our findings, no study could be isolated. Our observed distribution of CL in age group up to 19 years was statistically higher than what we expected for age group up to 19 years (adjusted expected) and our observed distribution of CL in age group 20-39 was lower than what we expected for age group 2039 (adjusted expected) and our observed distribution of $C L$ in age group $\geq 40$ years was statistically lower than what we expected for age group $\geq 40$ years (adjusted expected). No studies with hypothesis testing were found on literature search.

\subsection{Distribution of positive cases of cutaneous leishmaniasis by Residence $\left(\mathrm{H}_{03}\right)$}

The prevalence of $\mathrm{CL}$ in our study was more in rural $306(73.03 \%, 95 \% \mathrm{Cl} 68.78-77.28)$ than urban 113 (26.97\%, 95\% Cl 22.72-31.22) as per our confidence intervals.

Unlike our study, there was similar prevalence of $\mathrm{CL}$ in urban 38 (54.29\%, 95\% Cl 41.94-66.26) and rural $32(45.71 \%, 95 \% \mathrm{Cl} 33.74-58.06)$ as reported by Omari, et al. ${ }^{2}$ from Meknes Urban Subdivision of Fez-Meknes region, Central Morocco for the period from 2009-2015 reporting 70 confirmed cases of cutaneous leishmaniasis.

Our observed distribution of CL in rural was statistically higher than what we expected for rural (adjusted expected) and our observed distribution of $C L$ in urban was statistically lower than what we expected for urban (adjusted expected). No studies with hypothesis testing were found on literature search.

4.4 Marwat's Logical Trajectory of Research Process: This research project was designed by following the innovative logical and chronological flow of "Marwat's Logical Trajectory of Research Process". Here we cite few articles published on this format in Gomal Journal of Medical Sciences. ${ }^{14-18}$

\section{CONCLUSIONS}

The prevalence of cutaneous leishmaniasis in year 2020 in cutaneous leishmaniasis population of District D.I.Khan, Pakistan was higher in men than women, highest in age group up to 19 years than age groups $20-39$ and $\geq 40$ years, and higher in rural than urban. The prevalence for men was higher than expected for men and prevalence for women was lower than expected for women. The prevalence for age group up to 19 years was highest than expected for this age group than age groups 20-39 and $\geq 40$ years. The prevalence for rural was higher than expected for rural and the prevalence for urban was lower than expected for urban.

Acknowledgment: We deeply appreciate the supervision of this project by Dr. Muhammad Marwat (marwatmuhammad@gmail.com), who helped us altogether from conception, through planning, design, data collection, analysis \& interpretation, and write up. He also granted us permission to adopt his "Marwat Logical Trajectory of Research Process" for this project.

\section{REFERENCES}

1. Armijos RX, Weigel MM, Izurieta R, Racines J, Zurita C, Herrera W, Vega M. The epidemiology of cutaneous leishmaniasis in subtropical Ecuador. Trop Med Int Health 1997 Feb;2(2):140-52. https://doi. org/10.1046/j.1365-3156.1997.d01-236.x

2. El Omari H, Chahlaoui A, Talbi F, Ouarrak K, El Ouali Lalami A. Impact of Urbanization and Socioeconomic Factors on the Distribution of Cutaneous Leishmaniasis in the Center of Morocco. Interdiscip Perspect Infect Dis 2020 Jan 3;2020:2196418. https://doi.org/10.1155/2020/2196418

3. Aksoy M, Doni N, Ozkul HU, Yesilova Y, Ardic N, Yesilova A, Ahn-Jarvis J, Oghumu S, Terrazas C, Satoskar AR. Pediatric Cutaneous Leishmaniasis in an Endemic Region in Turkey: A Retrospective Analysis of 8786 Cases during 1998-2014. PLoS Negl Trop Dis. 2016 Jul 14;10(7):e0004835. https:// 
doi.org/10.1371/journal.pntd.0004835

4. Rajapaksa US, Ihalamulla RL, Udagedera C, Karunaweera ND. Cutaneous leishmaniasis in southern Sri Lanka. Trans R Soc Trop Med Hyg. 2007 Aug;101(8):799-803. https://doi.org/10.1016/j. trstmh.2006.05.013

5. Ayaz MM, Nazir MM, Ullah N, Zaman A, Akbar A, Zeeshan M, Hussain Z, Naz S, Zheng Y, Javed A, Lindsay DS. Cutaneous Leishmaniasis in the Metropolitan City of Multan, Pakistan, a Neglected Tropical Disease. J Med Entomol 2018 Jun 28;55(4):1040-1042. https://doi.org/10.1093/jme/ tjy003

6. Hayat U, Ayaz S, Akram M, Khattak AM. Cutaneous Leishmaniasis: its prevalence and role of PCR in its detection. J Islamabad Med Dent Coll 2015;4(1):15-8.

7. Rahim F, Jamal S, Raziq F, Uzair M, Sarwar B, Ali $\mathrm{H}$, et al. An outbreak of cutaneous leishmaniasis in a village of district Dir, NWFP. J Postgrad Med Inst 2003;17(1):85-9.

8. Jamal $Q$, Shah A, Ali N, Ashraf M, Awan MM, Lee C. Prevalence and Comparative Analysis of Cutaneous Leishmaniasis in Dargai Region in Pakistan. Pakistan J Zoo 2013; 45(2):537-41.

9. Ullah K, Khan NH, Sepúlveda N, Munir A, Wahid S. Assessing Incidence Patterns and Risk Factors for Cutaneous Leishmaniasis in Peshawar Region, Khyber Pakhtunkhwa, Pakistan. J Parasitol 2016; 102 (5): 501-6. https://doi.org/10.1645/15-919

10. Hussain M, Munir S, Khan TA, Khan A, Ayaz S, Jamal MA, Ahmed I, Aziz S, Watany N, Kasbari M. Epidemiology of Cutaneous Leishmaniasis Outbreak, Waziristan, Pakistan. Emerg Infect Dis. 2018 Jan;24(1):159-161. https://doi.org/10.3201/ eid2401.170358

11. Raosoft ${ }^{\circledR}$ online sample size calculator [Internet]. Raosoft Inc., Seattle, Washington 2004. [accessed 2020 Nov 20]. Available from: www.raosoft.com/ samplesize.html

12. Statistics Kingdom. Proportion confidence interval calculator [internet]. Statistics Kingdom; Melbourne, Australia 2007. [accessed 2020 Nov 22]. Available at: https://www.statskingdom. com/41_proportion_confidence_interval.html

13. Social Science Statistics. Statistical Tests Calculators [Internet]. [accessed 2020 Nov 22]. Available from: https://www.socscistatistics.com/tests/goodnesso $t /$ default2.aspx

14. Shah S, Basharat A, Shah M, Marwat M, Billah M, Ali SM. Frequency, distribution and presentation $\mathrm{n}$ of hypocalcemia in B-thalassemia major. Gomal J Med Sci 2018; 16:2-8. https://doi.org/10.46903/ gjms/16.01.1446

15. Ghori MR, Khan H, Marwat M. Distribution of non-malignant hematological disorders by sex, age groups and type of disease based on bone marrow aspiration in population of Khyber Pakhtunkhwa, Pakistan. Gomal J Med Sci 2019 Apr-Jun; 17 (2): 29-36. https://doi.org/10.46903/gjms/17.02.1926

16. Ain N, Khan S, Marwat M, Khan N, Ahmad I, Ramzan F, et al. Frequency, distribution and determinants of hypertension in adult stroke population of D.I.Khan Division, Pakistan. Gomal J Med Sci 2019 Jul-Sep; 17 (3):81-9. https://doi.org/10.46903/ gjms/17.03.2076

17. Marwat M, Ahmad I, Ashiq F, Ali S, Zamir S, Rehman $\mathrm{MU}$, et al. Frequency, distribution and determinants of diabetes mellitus in adult acute coronary syndrome population of D.I.Khan Division, Pakistan. Gomal J Med Sci 2019 Oct-Dec; 17 (4):131-43. https://doi.org/10.46903/gjms/17.04.2106

18. Khalid MK, Ahmad I, Khan MA, Sharjeel M, Irfan M. Marwat M. Distribution of pediatric cataracts by sex, age groups, laterality, type and presentation in population of D.I.Khan District, Pakistan. Gomal J Med Sci 2019 Oct-Dec; 17 (3):123-30. https://doi. org/10.46903/gjms/17.04.2025

\section{CONFLICT OF INTEREST \\ Authors declare no conflict of interest. GRANT SUPPORT AND FINANCIAL DISCLOSURE None declared.}

\section{AUTHORS' CONTRIBUTION}

The following authors have made substantial contributions to the manuscript as under:

Conception or Design:

Acquisition, Analysis or Interpretation of Data:

Manuscript Writing \& Approval:

$$
\begin{aligned}
& \text { MR, YR, MU, MY } \\
& \text { MR, YR, MU, MY, MB, MJ, AK, ZK, AW, NU } \\
& \text { MR, YR, MU, MY, MB, MJ, HU, ZKA, AK, AU }
\end{aligned}
$$

All the authors agree to be accountable for all aspects of the work in ensuring that questions related to the accuracy or integrity of any part of the work are appropriately investigated and resolved. 